\title{
Adaptive Change in Intra-Winter Distribution of Relatively Cold Events to East Asian Warming
}

\author{
Yong-Sang Choi ${ }^{1,2}$, Chang-Hoi Ho ${ }^{1,{ }^{*}}$, Dao-Yi Gong ${ }^{3}$, Jee-Hoon Jeong ${ }^{4}$, and Tae-Won Park ${ }^{1}$ \\ ${ }^{1}$ School of Earth and Environmental Sciences, Seoul National University, Seoul, Korea \\ ${ }^{2}$ Department of Earth, Atmospheric and Planetary Sciences, Massachusetts Institute of Technology, Cambridge, Massachusetts, USA \\ ${ }^{3}$ College of Resources Science and Technology, Beijing Normal University, Beijing, China \\ ${ }^{4}$ Department of Earth Sciences Centre, Gothenburg University, Gothenburg, Sweden
}

Received 8 August 2008, accepted 20 November 2008

\begin{abstract}
For the past few decades, daily winter temperatures over East Asia have been higher and less variable. Generally, these simple temperature-distribution shifts should lead to a decrease in the occurrence of cold extremes, but observations of the changes in the extremes are often complicated. In the present study, the change in the occurrence of relatively cold events (daily temperature anomaly, $\leq-2 \sigma$ for that season) in each winter monsoon over East Asia was examined using ground observations of daily temperature for the period 1954 - 2006. The time-mean temperature for each winter was subtracted to remove the interannual variability and long-term trend. Our analyses reveal that the intraseasonal temperature distribution over East Asia has changed with a negative skew, and the frequency of the relatively cold events has slightly increased (by 0.09 days per decade) over the past few decades, on an average, for the entire analysis domain (east of $105^{\circ} \mathrm{E}, 122$ stations). In particular, the increase occurs more dominantly ( $82 \%$ of the total stations) in regions north of $40^{\circ} \mathrm{N}$ where a stronger warming has progressed. The frequency of relatively cold events is found to be significantly correlated with the variance of the Siberian high and the mean of the Arctic Oscillation. The increasing trend in the frequency of relatively cold events may serve to partly countervail the decrease ( -1.12 days per decade) in the frequency of absolute cold events (daily temperature anomaly, $\leq 2 \sigma$ overall) across the entire observation period.
\end{abstract}

Key words: Relatively cold event, Temperature distribution, Global warming, East Asian winter monsoon, East Asia

Citation: Choi, Y. S., C. H. Ho, D. Y. Gong, J. H. Jeong, and T. W. Park, 2009: Adaptive change in intra-winter distribution of relatively cold events to east Asian warming. Terr. Atmos. Ocean. Sci., 20, 807-816, doi: 10.3319/TAO.2008.11.20.01(A)

\section{INTRODUCTION}

The climatological mean temperature is usually defined as the average for 30 years at the end of each decade. However, in daily temperature records, many values are not close to the average. To represent the spread in magnitude, the standard deviation $(\sigma)$ is derived as the normalized second statistical moment. When the distribution of temperature follows a normal distribution, assuming the frequency distributions of positive and negative anomalies are symmetrical, about $20(68 \%)$ of the 30 values are included within $\pm 1 \sigma$ from the average temperature. As long as such a distribution is maintained, an increase in the mean temperature would result in more frequent extreme warm events and less

\footnotetext{
* Corresponding author

E-mail:hoch@cpl.snu.ac.kr
}

frequent extreme cold events. In addition, a smaller variance would result in less frequent occurrences in both extreme warm and cold anomalies (IPCC 2007; references therein).

Changes in the frequency distribution of temperature may be caused by a shift in the mean, a change in the daily variance, or a combination of both, and may, therefore, represent more complex behaviors. Different combinations of mean and variance may produce vastly different features in the frequency distributions, depending on the exact distribution (Robeson 2002). In real observations, furthermore, temperature frequency distributions may show considerable asymmetry (Gong and Ho 2004; hereafter GH04).

Nakamura and Wallace (1991) suggested that most large anomalies with amplitudes larger than $2 \sigma$ in the sea-level 
pressure (SLP) field can be accounted for by variations in skewness, the normalized third statistical moment. Thus, variations in the skewness can be used for measuring changes in the frequency distributions, particularly large positive and negative anomalies (Garreaud 2001). GH04 presented an interesting result concerning mean-variance-skewness relations in the wintertime temperature change over East Asia. They found that the variance has decreased as the mean temperature increased during the past several decades, whereas the skewness coefficients show tendencies toward negative values. Their results suggest that a warming in East Asia may result in reduced up-and-down daily temperature variations, and more frequent "relatively" cold events (defined as daily temperature anomaly $\leq-2 \sigma_{i}$, where $\sigma_{i}$ indicates the intraseasonal standard deviation) during each winter; the term 'relatively' emphasizes anomalous temperature only on intraseasonal time scales. Such events form the low tail of the temperature frequency distribution for a given season; this is an important notion from the viewpoint of studies on intraseasonal variability as well as socioeconomic climate adaptation related to bodily sensations in the living. For example, dropped temperatures in the climate after 1976 can be higher than those in the climate before 1976, but its influence might be more severe for animals and plants which may be acclimated to the warmer present climate.

The results in GH04 seem to contradict the scientific consensus that global warming reduces the frequency of cold events (or cold extremes; Zhai et al. 1999; IPCC 2007). However, this is simply because the consensus is based on the common definition of a cold event, i.e., a daily temperature that is below $2 \sigma$ for the observations for the entire period, instead of $2 \sigma$ for each winter period (i.e., $2 \sigma_{i}$ ). We refer to this notion as the "absolute" cold event, to distinguish it from the relatively cold events. The difference between the absolute (a) and relative events (b) in East Asia during the winter monsoon season (November through March) is clearly represented in Fig. 1. We used observations from 122 stations for the period 1954 - 2006, which are extension of GH04 (detailed data descriptions in next section). The 5-year running mean and linear regression lines are represented by the thick black and dotted lines, respectively. An intriguing feature is that the frequency of absolute cold events has rapidly decreased (-1.1 days per decade; significant at the $99 \%$ significance level), while the frequency of relatively cold events has slightly increased ( 0.1 days per decade). Statistical significance of the trend in relatively cold events is weak due to the large interannual variability. The opposite trend is found for warm events ( 0.3 and -0.1 days per decade for the absolute and relatively warm events, respectively). Therefore, the change in the frequency of relatively intense events is opposite to that of the frequency of absolute intense events caused by a warming in East Asia.

In this study, the occurrence of the relatively cold events over East Asia was investigated on the basis of surface ob- servations of daily temperature in China and Korea for the period 1954 - 2006. The next section explains the data used and the methods to derive the relatively cold events. Section 3 shows the relation between the occurrence of relatively cold events and the changes in the temperature distribution (viz., mean, skewness, and variance). Section 4 discusses the impact of the large-scale atmospheric circulations such as Siberian High (SH) and Arctic Oscillation (AO) on intraseasonal temperature. Section 4 finally concludes this report.

\section{DATA AND METHOD}

The analysis domain was confined to East Asia (east of $105^{\circ} \mathrm{E}, 19^{\circ}-52^{\circ} \mathrm{N}$ ), where the East Asian winter monsoon system dominates surface climate during wintertime. Within the domain, 113 Chinese stations and 9 Korean stations were chosen. The daily temperatures for the Chinese stations were obtained from the China Meteorological Administration and those for the Korean stations, from the Korea Meteorological Administration. Over the entire analysis period 1954 2006, missing data constituted no more than four days worth

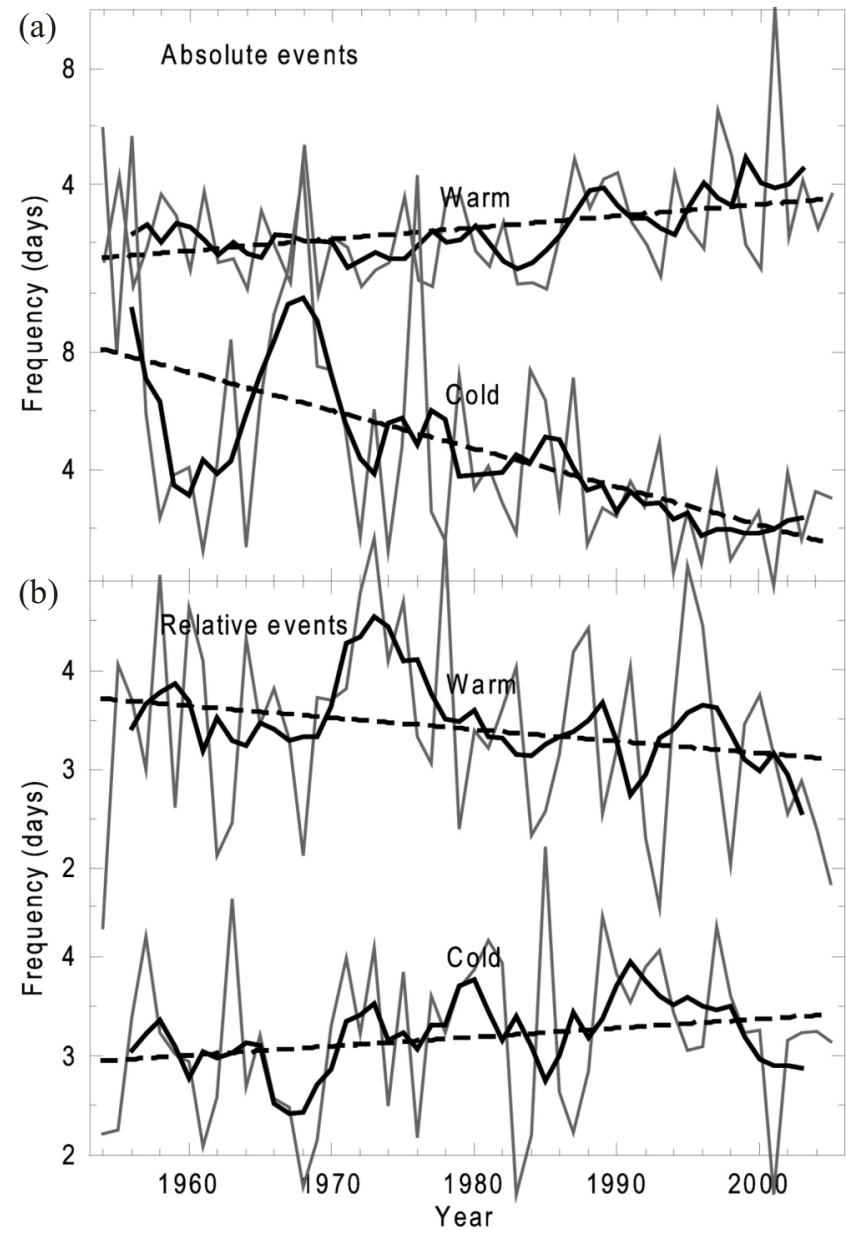

Fig. 1. Frequency of (a) absolute and (b) relatively cold and warm events in East Asia during winter monsoon. Thick solid and dotted lines are the 5-year running mean and linear trends of the time-series. 
at each station; all missing records were simply substituted with the mean temperatures for the 10 neighboring days (5 before and 5 after the "missing" day). The analysis period was the winter monsoon season (November 1 through March 31).

The daily temperature anomalies $\left(T^{\prime}\right)$ were derived by subtracting the annual cycle from the raw data. The annual cycle was estimated from a 21-day running mean ( \pm 10 days) of the simple mean over every 365 days for the entire period 1971/72 - 2000/01; i.e., a climatological mean value for a given calendar day was calculated based on 630 observations ( 30 years $\times 21$ days $=630$ days in total). The value on February 29 in the leap years was obtained by calculating the mean for February 28 and March 1. Then, the daily anomaly from the annual cycle $\left(T^{\prime}\right)$ was computed for each station for the whole period. In addition, the mean $T^{\prime}$ for a given winter was subtracted from the data for that winter to eliminate the differences in means among winters. This anomalous temperature $\left(T^{\prime \prime}\right)$ represents the deviation from the mean on an intraseasonal time scale.

The intraseasonal standard deviation $\sigma_{\mathrm{i}}$ for each winter at each station was estimated using the time series of $T^{\prime \prime}$ for 1954 - 2006. Accordingly, the value of $\sigma_{i}$ varies from year to year. In the present study, the relatively cold events are defined as days with $T^{\prime \prime} \leq-2 \sigma_{i}$; and similarly, relatively warm events are defined as days with $T^{\prime \prime} \geq+2 \sigma_{\mathrm{i}}$. We also determine the average frequencies of these relative events in each winter at each of the given stations $\left[F\left(T^{\prime \prime} \leq-2 \sigma_{\mathrm{i}}\right)\right.$, and $F\left(T^{\prime \prime} \geq\right.$ $\left.+2 \sigma_{\mathrm{i}}\right)$, respectively].

\section{CHANGE IN INTRA-WINTER DISTRIBUTION OF RELATIVELY COLD EVENTS}

The absolute cold events (i.e., $T^{\prime} \leq-2 \sigma$ ) may commonly correspond to the frost days or cold extremes in the records. Then, the question is: Are the relatively cold events (i.e., $T^{\prime \prime}$ $\leq-2 \sigma_{i}$ ) also substantially cold? In order to understand the range of temperature during the relatively cold events, the distribution, mean, median, and variability of real temperatures during the absolute and relatively cold events are shown in Fig. 2. All regions are divided into three subgroups: the northern region for the most northerly stations (north of $40^{\circ} \mathrm{N}$; 44 stations), the central region $\left(30^{\circ}-40^{\circ} \mathrm{N}\right.$; 45 stations), and the southern region for the most southerly stations (south of $30^{\circ} \mathrm{N} ; 33$ stations).

Figure 2 reveals that the relatively cold events have a similar temperature range to those of the absolute cold events (compare Figs. 2a and $\mathrm{b}$ ). The average temperatures of the absolute cold events are $-20.9^{\circ},-5.4^{\circ}$, and $5.4^{\circ} \mathrm{C}$ in the northern, central, and southern regions, respectively (Fig. 2a). The average temperatures of the relatively cold events are a few degrees $\left(\sim 1^{\circ}-2^{\circ} \mathrm{C}\right)$ higher: $-19.2^{\circ},-4.5^{\circ}$, and $6.1^{\circ} \mathrm{C}$, respectively (Fig. $2 \mathrm{~b}$ ). The real temperatures are largely anomalous beyond $\pm 10^{\circ} \mathrm{C}$ from the average temperature.
Therefore, the relatively cold events are as cold as the absolute cold events get. None of the relatively cold events are absolutely warm, but most of them belong to the absolute cold events. The percentage of the events of absolutely low temperature to the total relatively cold events has decreased due to the decrease in the absolute events for the past decades (figure not shown). In addition to the difference between the absolute and relative events, it should be noted that the temperatures of both types of cold events are considerably higher in the southern region than in the northern region. This regional discrepancy also represents the relativity of the cold events considered in this general climate study.

We examined the rate of change in the frequency of the relatively cold and warm events, $F\left(T^{\prime \prime} \leq-2 \sigma_{\mathrm{i}}\right)$ and $F\left(T^{\prime \prime} \geq\right.$ $+2 \sigma_{\mathrm{i}}$ ), respectively, for the period $1954-2006$ (Fig. 3). The interannual variations in the frequency of the events are so large that they weaken the statistical significance of the estimated long-term change rate. Thus we used a 5-year running-mean smoother to extract the variations of the events in decadal and longer timescales. The rate of change in filtered data was then calculated using an ordinary least squares method. The effective degrees of freedom estimated by the autoregressive properties (Davis 1976) of the filtered time series were roughly 10 , which are thus assumed for the paired t-test of the estimated rate of change in Fig. 3 (square for significant stations at the $90 \%$ confidence level). The values in filtered data are also summarized in Table 1, together with the values in unfiltered data.

For the occurrences of relatively cold events, the vast majority of the analysis domain exhibits an increasing tendency. Among all 122 stations, 85 (70\% of the total) have positive trends (Fig. 3a). It is noteworthy that none of negative values are significant at the $90 \%$ confidence level. Such spatial consistency in the rate of change should provide extra confidence. In general, the increasing trend is more dominant at the northern stations. The frequency of the relatively cold events increases at $36(82 \%)$ of the 44 northern stations. Among the central 45 and the 33 southern stations, an increase in frequency is only observed at $30(67 \%)$ and 19 $(58 \%)$ stations, respectively. In the northern region, the rate of change of $F\left(T^{\prime \prime} \leq-2 \sigma_{\mathrm{i}}\right)$ is, on average, 0.11 days per decade in filtered data (Table 1). The trend is smaller in the central region ( 0.08 days per decade) and southern region ( 0.06 days per decade). On average, the entire region shows a rate of change of 0.09 days per decade in filtered data. These rates in filtered data are similar to that in unfiltered data (Table 1); however, their statistical significance is much stronger due to the highly variable frequencies. After the data is filtered, the rates became significant at the $95 \%$ and $90 \%$ confidence levels despite small degrees of freedom (Table 1).

On the other hand, using the shorter period until the year of 2000 (the analysis period of GH04), the estimated 

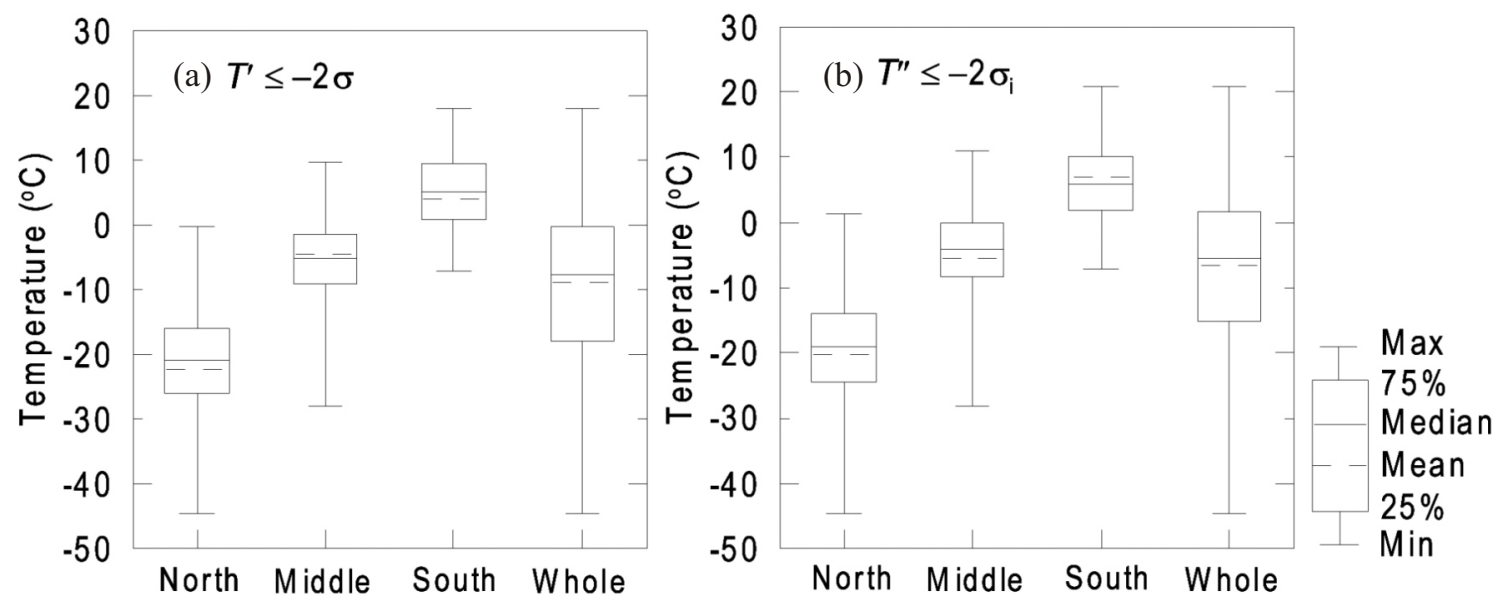

Fig. 2. Real temperature distribution of (a) $T^{\prime} \leq-2 \sigma$ events and (b) $T^{\prime \prime} \leq-2 \sigma$ events for northern region (north of $\left.40^{\circ} \mathrm{N}\right)$, central region $\left(40^{\circ}-30^{\circ} \mathrm{N}\right.$ ), southern region (south of $30^{\circ} \mathrm{N}$ ), and entire study area.

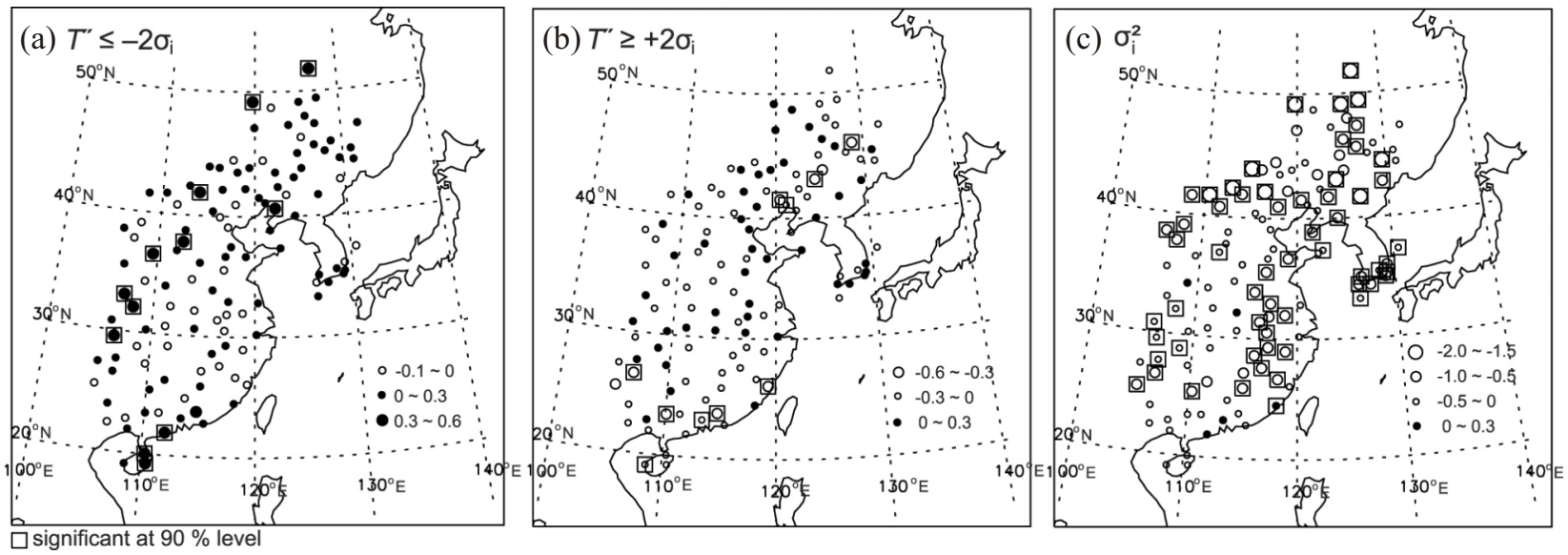

Fig. 3. Trends of (a) frequency of relatively cold events $\left(T^{\prime \prime} \leq-2 \sigma\right)$, (b) frequency of relatively warm events $\left(T^{\prime \prime} \geq+2 \sigma\right)$, and (c) intraseasonal variance of daily temperature. Units for (a) and (b) are days per decade, and for (c), ${ }^{\circ} \mathrm{C}^{2}$ per decade. Linear trends are estimated using the ordinary least squares method in filtered data for the period 1954 - 2006.

Table 1. Rate of change of the mean, variance, and frequency of relatively intense events for unfiltered and filtered data for the period 1954 2006. Shown in parentheses are the data for the period considered by Gong and Ho (2004), i.e., 1954 - 2000.

\begin{tabular}{|c|c|c|c|c|c|c|c|c|}
\hline \multirow[b]{2}{*}{ Region } & \multicolumn{4}{|c|}{ Unfiltered } & \multicolumn{4}{|c|}{ Filtered } \\
\hline & $\begin{array}{c}\bar{T} \\
{ }^{\circ} \mathrm{C} / 10 \mathrm{y}\end{array}$ & $\begin{array}{l}\sigma_{\mathrm{i}}^{2}\left(T^{\prime \prime}\right) \\
{ }^{\circ} \mathrm{C}^{2} / 10 \mathrm{y}\end{array}$ & $\begin{array}{c}F\left(T^{\prime \prime} \leq-2 \sigma_{\mathrm{i}}\right) \\
\text { days } / 10 \mathrm{y}\end{array}$ & $\begin{array}{c}F\left(T^{\prime \prime} \geq+2 \sigma_{\mathrm{i}}\right) \\
\text { days } / 10 \mathrm{y}\end{array}$ & $\begin{array}{c}\bar{T} \\
{ }^{\circ} \mathrm{C} / 10 \mathrm{y}\end{array}$ & $\begin{array}{l}\sigma_{\mathrm{i}}^{2}\left(T^{\prime \prime}\right) \\
{ }^{\circ} \mathrm{C}^{2} / 10 \mathrm{y}\end{array}$ & $\begin{array}{c}F\left(T^{\prime \prime} \leq-2 \sigma_{\mathrm{i}}\right) \\
\text { days } / 10 \mathrm{y}\end{array}$ & $\begin{array}{c}F\left(T^{\prime \prime} \geq+2 \sigma_{\mathrm{i}}\right) \\
\text { days } / 10 \mathrm{y}\end{array}$ \\
\hline Northern & $\begin{array}{c}0.50^{\mathrm{a}} \\
\left(0.50^{\mathrm{a}}\right)\end{array}$ & $\begin{array}{l}-0.76^{\mathrm{b}} \\
\left(-0.90^{\mathrm{b}}\right)\end{array}$ & $\begin{array}{l}0.12 \\
\left(0.24^{b}\right)\end{array}$ & $\begin{array}{c}-0.07 \\
(-0.13)\end{array}$ & $\begin{array}{c}0.49^{\mathrm{a}} \\
\left(0.55^{\mathrm{a}}\right)\end{array}$ & $\begin{array}{l}-0.61^{\mathrm{b}} \\
\left(-1.02^{\mathrm{a}}\right)\end{array}$ & $\begin{array}{c}0.11^{\mathrm{c}} \\
\left(0.27^{\mathrm{a}}\right)\end{array}$ & $\begin{array}{l}-0.08^{\mathrm{b}} \\
\left(-0.12^{\mathrm{b}}\right)\end{array}$ \\
\hline Central & $\begin{array}{c}0.31^{\mathrm{a}} \\
\left(0.30^{\mathrm{a}}\right)\end{array}$ & $\begin{array}{l}-0.46^{\mathrm{b}} \\
\left(-0.65^{\mathrm{b}}\right)\end{array}$ & $\begin{array}{c}0.07 \\
(0.14)\end{array}$ & $\begin{array}{c}0.00 \\
(0.00)\end{array}$ & $\begin{array}{c}0.31^{\mathrm{a}} \\
\left(0.23^{\mathrm{a}}\right)\end{array}$ & $\begin{array}{l}-0.39^{\mathrm{a}} \\
\left(-0.56^{\mathrm{a}}\right)\end{array}$ & $\begin{array}{c}0.08^{\mathrm{c}} \\
\left(0.10^{\mathrm{c}}\right)\end{array}$ & $\begin{array}{c}-0.02 \\
(-0.01)\end{array}$ \\
\hline Southern & $\begin{array}{c}0.18^{\mathrm{b}} \\
\left(0.17^{\mathrm{b}}\right)\end{array}$ & $\begin{array}{l}-0.33 \\
(-0.46)\end{array}$ & $\begin{array}{c}0.08 \\
(0.10)\end{array}$ & $\begin{array}{c}-0.12 \\
(-0.03)\end{array}$ & $\begin{array}{c}0.18^{\mathrm{a}} \\
\left(0.09^{\mathrm{a}}\right)\end{array}$ & $\begin{array}{l}-0.34^{\mathrm{a}} \\
\left(-0.40^{\mathrm{b}}\right)\end{array}$ & $\begin{array}{c}0.06 \\
\left(0.11^{\mathrm{c}}\right)\end{array}$ & $\begin{array}{l}-0.12^{\mathrm{b}} \\
(-0.03)\end{array}$ \\
\hline Whole & $\begin{array}{c}0.35^{\mathrm{a}} \\
\left(0.33^{\mathrm{a}}\right)\end{array}$ & $\begin{array}{l}-0.53^{b} \\
\left(-0.69^{b}\right)\end{array}$ & $\begin{array}{c}0.09 \\
\left(0.17^{\mathrm{c}}\right)\end{array}$ & $\begin{array}{l}-0.06 \\
(-0.06)\end{array}$ & $\begin{array}{c}0.34^{\mathrm{a}} \\
\left(0.31^{\mathrm{a}}\right)\end{array}$ & $\begin{array}{l}-0.46^{\mathrm{a}} \\
\left(-0.68^{\mathrm{a}}\right)\end{array}$ & $\begin{array}{c}0.09^{\mathrm{b}} \\
\left(0.17^{\mathrm{a}}\right)\end{array}$ & $\begin{array}{l}-0.07^{\mathrm{a}} \\
\left(-0.07^{\mathrm{b}}\right)\end{array}$ \\
\hline
\end{tabular}

${ }^{a}$ Significant at the $99 \%$ confidence level, ${ }^{b}$ at $95 \%,{ }^{c}$ at $90 \%$. 
rate of change in filtered data is 0.27 days per decade for the northern region and is 0.17 days per decade for the whole analysis region, which is somewhat different from that of the longer period. Consideration of the recent six more years may also affect significance of the rate of change in both unfiltered and filtered data. This implies that our 53-year observations cannot yet provide a definite indication of longterm change rates beyond the sign (i.e., positive or negative change), as the interannual variations in frequency of the relatively cold event is extremely large.

Conversely, the spatial distribution of relatively warm events shows nearly the opposite pattern (Fig. 3b). Negative (positive) values appear at 80 (42) stations; none of positive values are significant at the $90 \%$ confidence level. Both negative and positive values are scattered everywhere. The rate of change of $F\left(T^{\prime \prime} \geq+2 \sigma_{\mathrm{i}}\right)$ is the smallest in the southern region ( -0.12 days per decade, Table 1$)$, but for the shorter period until 2000, the northern region has the minimum ( -0.12 days per decade). The significance of the trends becomes stronger when the recent six more years is included. In general, the changes in the frequencies of the relatively cold and warm events both display stronger negative trends in the northern region than in the other regions.

It is notable that these regional patterns are similar to those of the mean temperature (Table 1), with greater warming being observed at the northern stations and weaker warming at the southern stations. Therefore, warm winters are accompanied by more frequent relatively cold events, and cold winters by fewer relatively cold events. This is apparently contrary to the common belief regarding the meanextreme relationships on interannual or longer time scales. As shown in Fig. 1, the most important reason for the discrepancy is the use of $T^{\prime \prime}$ instead of $T^{\prime}$ in the calculations for the frequency of intense events. We also checked the spatial pattern of the frequency of absolute events (i.e., using $T^{\prime}$ ); this yielded significant decreasing trends in the occurrences of the absolute cold events and significant increasing trends in the occurrences of absolute warm events over the entire analysis region.

Since our results are based on $T^{\prime \prime}$, which eliminates differences in mean across different winters, the changes in the relative events should be related to the intraseasonal temperature variance. Smaller variance can lead to more frequent relatively cold and warm events, all else being equal. To clarify this issue, we computed the change of the intraseasonal variance of daily temperature anomalies (Fig. 3c). The variance displays overwhelmingly negative change rates. Among the 122 stations, 115 stations (94\%) show negative values. The largest changes are found in the northern region: $-0.61^{\circ} \mathrm{C}^{2}$ per decade (Table 1). Over the central and southern regions, the values become smaller: $-0.39^{\circ} \mathrm{C}^{2}$ per decade and $-0.34^{\circ} \mathrm{C}^{2}$ per decade, respectively. The average at all stations in the analysis domain exhibits a significant decreasing rate of $-0.46^{\circ} \mathrm{C}^{2}$ per decade. The rates in un- filtered data are generally stronger than these values.

Figure 4 shows that the long-term trend and year-to-year variation of the variance (gray bar) bear some likeness to those of the relatively cold events (solid line). The dotted line is the linear trend of the time-series of the frequency of the relatively cold event. It is also found that the recent increase in variance occurred after the mid-1990 and was accompanied by the recent decrease in the frequency of relatively cold events. These results suggest that the change in the variance is associated with that in the frequency of relatively cold events in winter over East Asia. The relationship between the frequency of relative events and the variance is particularly evident in the northern and entire domain (Fig. 4), with correlation coefficients $(r)$ of -0.27 and -0.24 , respectively (significant at the $90 \%$ confidence level). For the central region, the correlation is -0.21 , which is also significant. For the southern region, the correlation is not significant $(r=-0.04)$.

Since relatively cold events are taken by satisfying $T^{\prime \prime} \leq$

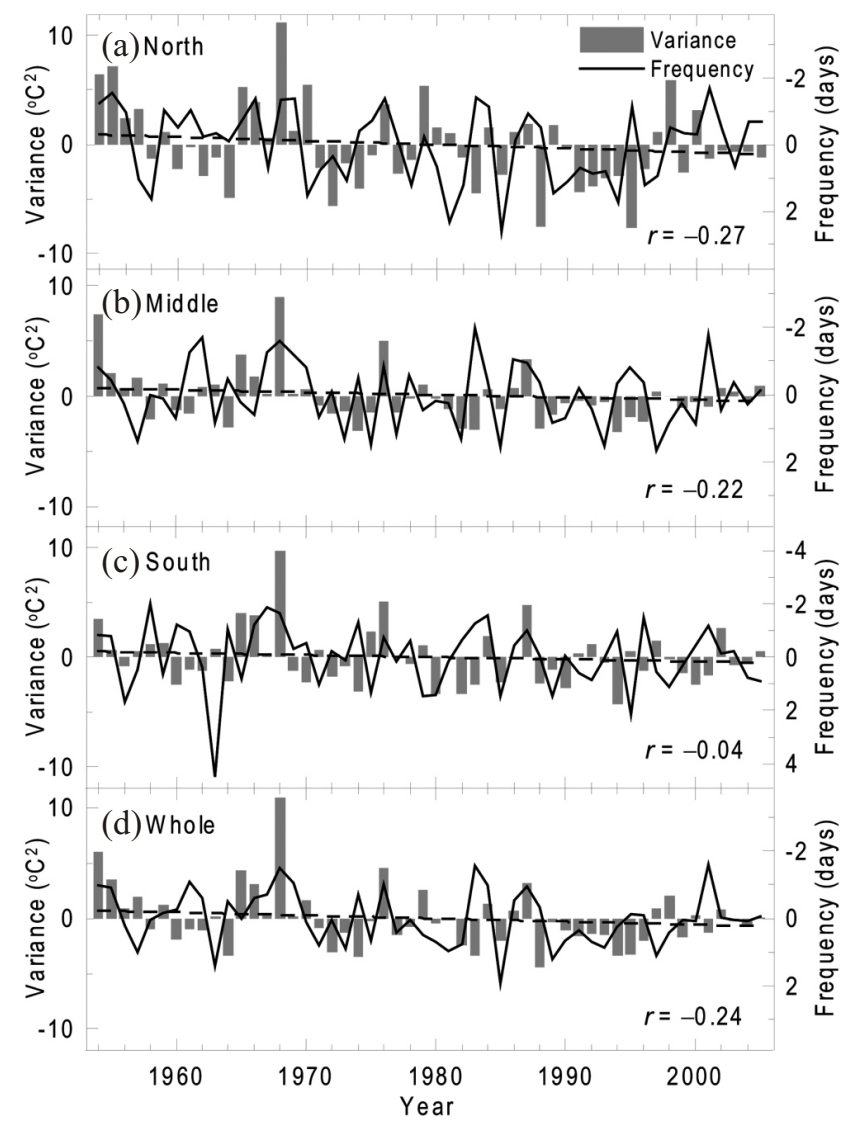

Fig. 4. Regional mean frequency of $T^{\prime \prime} \leq-2 \sigma$ events (solid lines). Shown as gray bars are the mean variances for the respective regions. All data are shown as anomalies for 1971/72 - 2005/06. Shown are (a) northern region (north of $40^{\circ} \mathrm{N}$ ), (b) central region $\left(40-30^{\circ} \mathrm{N}\right.$ ), (c) southern region (south of $30^{\circ} \mathrm{N}$ ), and (d) entire analysis domain. To facilitate comparison, the vertical axes for the variance curves are reversed. Dotted lines are linear trends of the time-series of the frequency. 
$-2 \sigma_{i}$, the decrease in variance in the intra-winter temperature distribution $\left(\sigma_{\mathrm{i}}^{2}\right)$, namely, the lower criterion can increase the frequency of relatively cold events. However, the decrease in the frequency of relatively warm events $\left(T^{\prime \prime} \geq+2 \sigma_{\mathrm{i}}\right)$ cannot be explained in this manner, and other changes in the temperature distribution such as a shift in the asymmetry must be factored in. The temperature variance differs from station to station and from one winter to the next. To make the intra-winter temperature distributions have an equal mean and variance, we normalize the temperature anomalies with respect to each winter period $\left(T^{\prime \prime} / \sigma_{\mathrm{i}}\right)$ prior to the analysis.

The probability density function (PDF) of $T^{\prime \prime} / \sigma_{\mathrm{i}}$ is compared over the five years with the highest frequency of relatively cold events and the five years with the lowest frequency (Fig. 5). The PDF is defined in the form of a relative frequency (expressed as a percentage). The three subregions and entire domain as a whole all clearly display similar features. On the negative anomaly side, the frequency of events with $-2 \sigma_{\mathrm{i}}<T^{\prime \prime}<0$ generally decreases, while the frequency of events with $T^{\prime \prime} \leq-2 \sigma_{\mathrm{i}}$ increases in all cases. Obviously, it is the change on the far left hand side (i.e., the very large negative anomaly side) of the distribution that results in the evident change of frequency of relatively cold events. This agrees fairly well with the increase in the frequency of relatively cold events in these regions. More importantly, we find that the changes in the distribution are clearly asymmetric on both sides. The changes on the negative side are evidently substantial. This might be due to the fact that the daily temperature over the analysis domain is strongly influenced by the cold events in association with East Asian winter monsoon activity. We note that, regardless of region, the skewness coefficient (i.e., the third moment) of the PDF of $T^{\prime \prime} / \sigma_{\mathrm{i}}$ is positive for the lower $F\left(T^{\prime \prime} \leq-2 \sigma_{\mathrm{i}}\right)$, while it is negative for the higher $F\left(T^{\prime \prime} \leq-2 \sigma_{\mathrm{i}}\right)$.

In addition, we study the PDF differences in association with the mean temperatures. The distributions of the PDFs for the five warmest and five coldest winters are generally similar to that shown in Fig. 5 in each respective region (Fig. 6). It is noted that all the selected warmer winters are later than the colder winters due to the recent warming in East Asia. The coldest winters occurred in: 1954, 1956, 1967, 1969, and 1976, and the warmest winters occurred in:
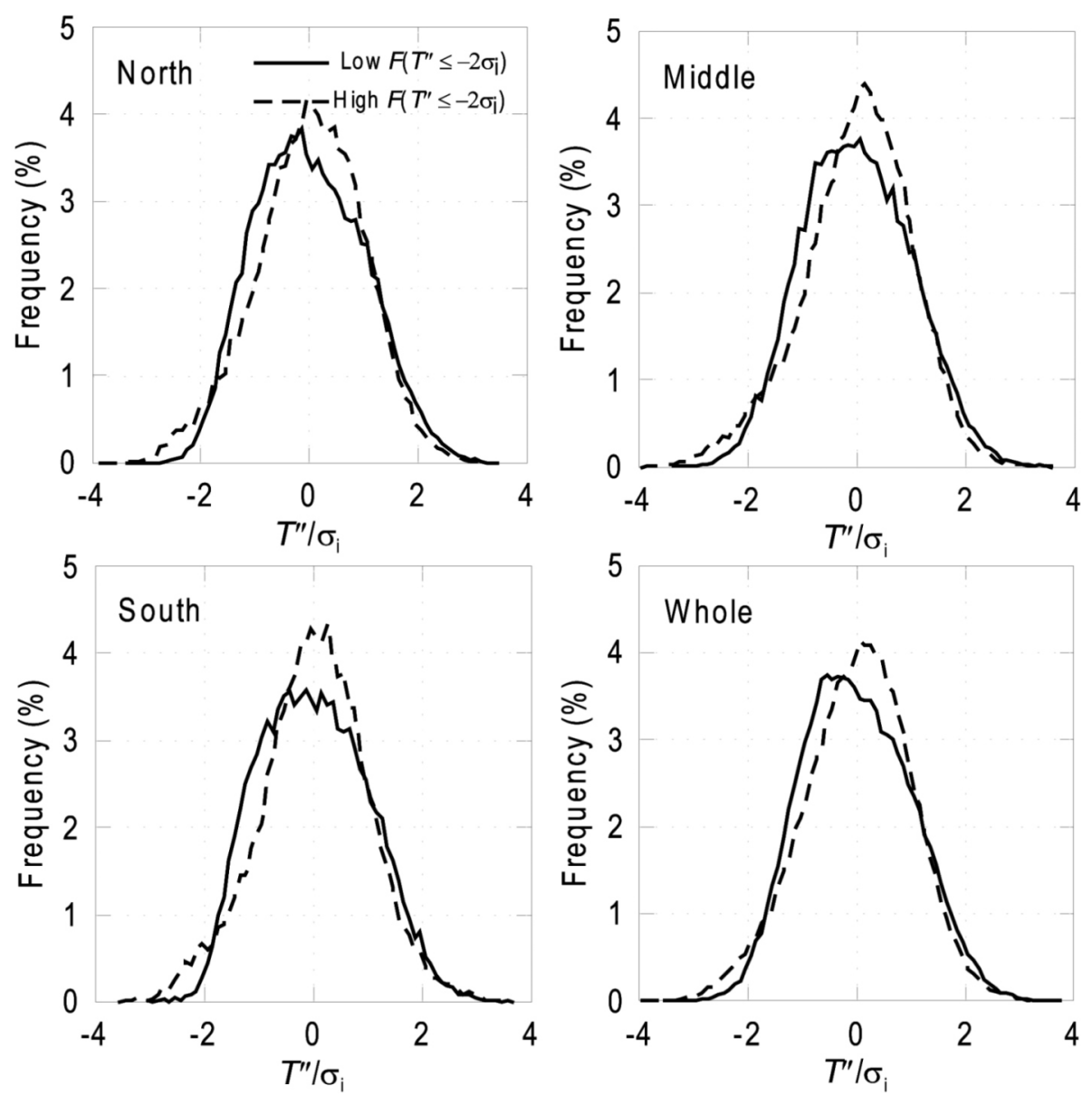

Fig. 5. Change in the distribution of daily temperature anomalies. For the northern region, central region, southern region, and entire analysis domain. Solid lines are the mean values for the 5 years with the lowest frequency of relatively cold events, and dashed lines for the 5 years with the highest frequency of relatively cold events. 

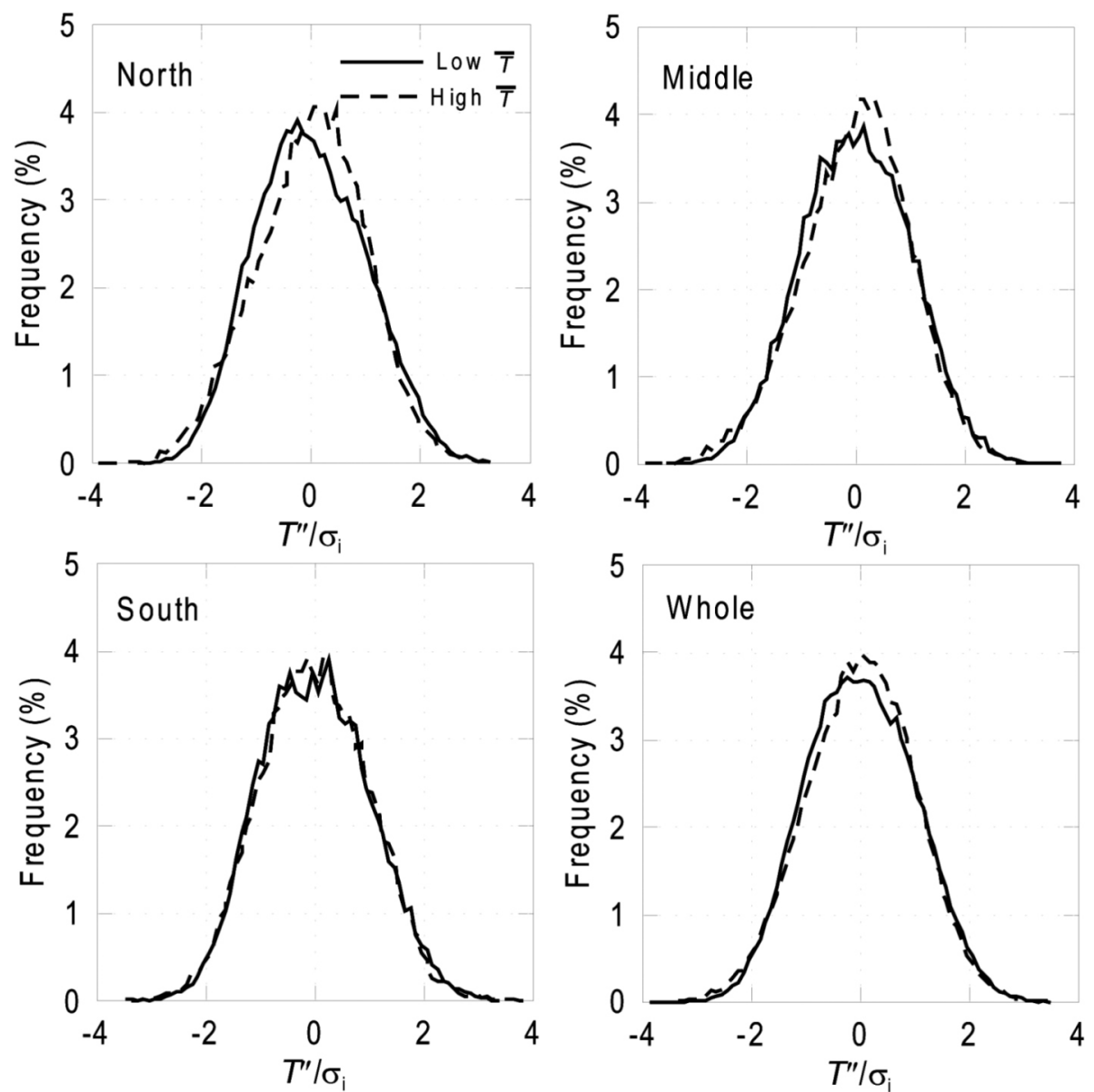

Fig. 6. Change in the distribution of daily temperature anomalies. For the northern, the central, the southern, and the entire region. Solid lines are the mean values for the 5 coldest years, and dashed lines for the 5 warmest years.

$1988,1990,1994,1997$, and 1998 on average for the whole domain. The main difference between the coldest winters and the warmest winters is in normal days $\left(-\sigma_{\mathrm{i}}<T^{\prime \prime}<+\sigma_{\mathrm{i}}\right)$. This implies that warm or cold years are determined by seasonal mean conditions of high-latitude forcing. During warm years the high-latitude forcing is weak so the temperature fluctuation/variance is small, while during the cold years the forcing is strong and the variance is large. The high-latitude forcing can be modulated by Siberian High (SH) and Arctic Oscillation (AO) as discussed in the next section.

Figure 6 also shows that the changes are asymmetric on both sides. The decreasing frequency of events with $-2 \sigma_{i}<$ $T^{\prime \prime}<0$ and increasing frequency of events with $T^{\prime \prime} \leq-2 \sigma_{\mathrm{i}}$ in warmer winters are most evident in the northern, central, and entire region. As a result, the PDF of $T^{\prime \prime} / \sigma_{\mathrm{i}}$ is positively skewed for the colder winters, while it is negatively skewed for the warmer winters. The southern region shows almost similar PDFs for the two periods, with positive skewness coefficients. This means more relatively cold events should be expected in the warmer winters, during which the variance also tends to become smaller simultaneously.

Can less frequent absolute cold events in warmer win- ters lead to such negative skewness or smaller variance? If the less frequent absolute cold event were the cause, it would lead to positive skew, not to negative skew. Because absolute warm events become more frequent on the other side, smaller variance cannot simply be explained by less frequent absolute cold event. After all, the skewness and the variance of the intraseasonal temperature distribution may not be related to the frequency of the absolute events.

\section{DISCUSSION}

Daily temperature fluctuations and intense cold and warm events often result directly from synoptic activities. Low-frequency variations in large-scale atmospheric circulations also exert an extensive influence on the high-frequency variability of surface temperature (Thompson and Wallace 2001; Higgins et al. 2002; Wettstein and Mearns 2002). Previous studies have found that a considerable portion of the monthly seasonal-mean temperature variation in East Asia is related to the $\mathrm{SH}$ and $\mathrm{AO}$ (Gong et al. 2001; Wu and Wang 2002; Jeong and Ho 2005, Jeong et al. 2006; Park et al. 2008). 
In Table 2, we have derived various statistical variables (means, variances, and relatively low and high events) of the $\mathrm{SH}$ and $\mathrm{AO}$, and have investigated their relations with the variance and frequency of relatively cold events in terms of surface temperature. Here, the variables measuring $\mathrm{AO}$ and $\mathrm{SH}$ are based on daily data sets. Indices for the $\mathrm{SH}$ are averaged over the domain $90^{\circ}-110^{\circ} \mathrm{E}, 45^{\circ}-55^{\circ} \mathrm{N}$, where the center of SLP variance is determined by empirical orthogonal function analysis (GH04). SLP data were taken from the NCEP/NCAR reanalysis data sets (Kalnay et al. 1996). The daily SLP anomaly of SH ( $\left.S H^{\prime \prime}\right)$ was obtained by the same method as that used for the temperature. Relatively intense events in $\mathrm{AO}$ and $\mathrm{SH}$ were also defined by using the same criterion as that for temperature, i.e., anomalies in excess of $+2 \sigma_{\mathrm{i}}$ or below $-2 \sigma_{\mathrm{i}}$.

Among the eight variables, only five of them including the SH-related variables and the winter mean of the AO index, show significant correlation at the $90 \%$ confidence level to the temperature variance or relatively cold events (Table 2). The other AO-related variables, including the variance and the frequency of the relatively intense events, have no significant correlation with surface temperatures. For the northern region, three variables (i.e., the mean $\mathrm{SH}$, $\mathrm{SH}$ variance, and mean $\mathrm{AO}$ ) are significantly correlated with $F\left(T^{\prime \prime} \leq-2 \sigma_{\mathrm{i}}\right)$. For the central region, only two variables (i.e., the frequency of relatively high and low $\mathrm{SH}$ anomalies) exhibits a significant correlation with $F\left(T^{\prime \prime} \leq-2 \sigma_{\mathrm{i}}\right)$. No significant factor is found relating to $F\left(T^{\prime \prime} \leq-2 \sigma_{\mathrm{i}}\right)$ in the southern region. Over the entire domain, the influence of SH variance and mean $\mathrm{AO}$ on the frequency of relatively cold events is apparent. It is noted that the variance of $\mathrm{SH}$ and the mean $\mathrm{AO}$ exhibit an even stronger correlation with temperature variance for all regions. In addition, the signs of correlation are reversed between the variance and the relatively cold events. The temperature variance increases and the frequency of relatively cold events decreases with the variance of
$\mathrm{SH}$. The temperature variance decreases with the mean $\mathrm{AO}$, while the frequency of relatively cold events increases.

The mean AO is known to not only influence the mean pressure in the low troposphere, but also its variance. The correlation between the mean $\mathrm{AO}$ and the $\mathrm{SH}$ variance is about -0.45 , which is significant at the $99 \%$ confidence level. A stronger positive phase of AO usually generates a much smaller intraseasonal variance in the $\mathrm{SH}(\mathrm{GH} 04)$, and consequently diminishes the variance of surface temperatures in East Asia. Our results indicate that the increasing change in the frequency of the relatively cold events is most likely associated with the reduced variance of SH (Table 2).

The increasing trend in the frequency of relatively cold events shown in this study is contrary to the behavior of the absolute cold events reported in previous studies (e.g., Zhai et al. 1999; IPCC 2007). The response of absolute cold events to the same atmospheric circulation changes is also the opposite to that of the relatively cold events; in other words, the smaller day-to-day variability of the $\mathrm{SH}$ during the positiveAO period leads to a reduction in the frequency of absolute cold events (or cold extremes) in East Asia (Jeong and Ho 2005). The disagreement arises from the differences in the criteria used and the analysis approach applied ( $T^{\prime}$ versus $\left.T^{\prime \prime}\right)$. The previous studies applied a fixed criterion estimated from multi-year climate data. The statistical characteristics of the air temperature in a large region cannot be represented by the data in one year. This is why absolute cold events were identified on the basis of a fixed criterion from multiyear climate data. This actually makes more sense than the relative cold events in order to count the events of real cold temperatures. Thus the decreasing frequency of absolute cold events identified by this approach is, to a large degree, related to the large increase in the mean winter temperature. In contrast, regardless of the mean temperature changes, our analysis is concerned with the relative events within the winter seasons, which are tightly connected with the variance

Table 2. Correlation between atmospheric circulation indices and temperature time series for different regions.

\begin{tabular}{lcccccccc}
\hline & \multicolumn{3}{c}{ Variance of temperature $\left[\sigma_{\mathrm{i}}^{2}\left(\boldsymbol{T}^{\prime \prime}\right)\right]$} & \multicolumn{3}{c}{ Relatively cold events $\left[F\left(\boldsymbol{T}^{\prime \prime} \leq-2 \sigma_{\mathrm{i}}\right)\right]$} \\
\cline { 2 - 9 } & Northern & Central & Southern & Whole & Northern & Central & Southern & Whole \\
\hline$\overline{S H}$ & 0.10 & 0.21 & 0.10 & 0.15 & $-0.35^{\mathrm{a}}$ & -0.07 & 0.16 & -0.14 \\
$\sigma_{\mathrm{i}}^{2}\left(S H^{\prime \prime}\right)$ & $0.56^{\mathrm{a}}$ & $0.76^{\mathrm{a}}$ & $0.64^{\mathrm{a}}$ & $0.70^{\mathrm{a}}$ & $-0.46^{\mathrm{a}}$ & -0.14 & 0.00 & $-0.29^{\mathrm{b}}$ \\
$F\left(S H^{\prime \prime} \geq+2 \sigma_{\mathrm{i}}\right)$ & -0.20 & $-0.31^{\mathrm{b}}$ & $-0.30^{\mathrm{b}}$ & $-0.28^{\mathrm{b}}$ & 0.13 & $0.26^{\mathrm{c}}$ & 0.14 & $0.24^{\mathrm{c}}$ \\
$F\left(S H^{\prime \prime} \leq-2 \sigma_{\mathrm{i}}\right)$ & 0.00 & 0.04 & 0.11 & 0.04 & 0.00 & $-0.28^{\mathrm{b}}$ & -0.13 & -0.18 \\
$\overline{A O}$ & $-0.51^{\mathrm{a}}$ & $-0.57^{\mathrm{a}}$ & $-0.38^{\mathrm{a}}$ & $-0.55^{\mathrm{a}}$ & $0.32^{\mathrm{b}}$ & 0.21 & 0.04 & $0.28^{\mathrm{b}}$ \\
$\sigma_{\mathrm{i}}{ }^{2}\left(A O^{\prime \prime}\right)$ & 0.21 & 0.11 & 0.14 & 0.18 & -0.03 & -0.06 & -0.03 & -0.05 \\
$F\left(A O^{\prime \prime} \geq+2 \sigma_{\mathrm{i}}\right)$ & -0.06 & -0.02 & -0.08 & -0.06 & 0.00 & -0.06 & -0.07 & -0.06 \\
$F\left(A O^{\prime \prime} \leq-2 \sigma_{\mathrm{i}}\right)$ & -0.05 & -0.02 & 0.04 & -0.02 & -0.08 & 0.20 & 0.20 & 0.13 \\
\hline
\end{tabular}

${ }^{a}$ Significant at the $99 \%$ confidence level, ${ }^{b}$ at $95 \%,{ }^{c}$ at $90 \%$. 
and skewness of the intraseasonal temperature distribution.

Figure 7 schematically shows the change from a distribution in the 1960s (in the cold climate) into a synthetic "normal" distribution (a) and into an actual "skewed" distribution in the 1990s (in the warm climate) (b). The mean and standard deviation of the distribution in the cold climate $\left(\mathrm{m}_{1}, \sigma_{1}\right)$ and the warm climate $\left(\mathrm{m}_{2}, \sigma_{2}\right)$ are $(-0.90,4.00)$ and $(0.45,3.65)$, respectively. The synthetic normal distribution in the warm climate (Fig. 7a) is calculated from a simple shift of the distribution in the 1960s to have the statistical values $\left(\mathrm{m}_{2}, \sigma_{2}\right)$ without the change of skewness. It is clearly shown that the absolute cold events identified by a fixed criterion $(-2 \sigma$ of the multi-year climate data) have decreased dramatically due to a shift of the distribution from the cold climate to the warm climate. Comparing the synthetic normal distribution and the actual skewed distribution in the warm climate, the skewed distribution appears to contain

(a) Normal distribution in warm climate

(b) Skewed distribution in warm climate

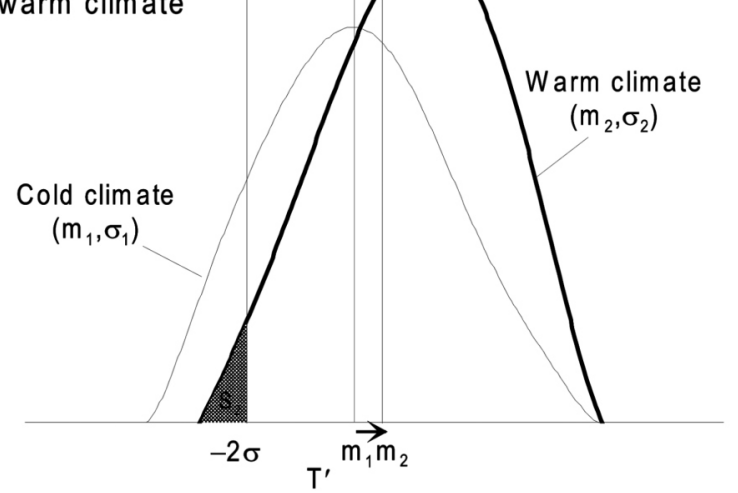

Fig. 7. Schematic of a distribution in the cold climate (in the 1960s) versus a distribution in the warm climate of temperatures. The distribution in the warm climate is taken from a simple shift of the distribution in the 1960s to have the same mean and standard deviation as that of the 1990s (a), and the distribution in the 1990s (b). $\mathrm{m}_{1}, \sigma_{1}$, and $\mathrm{S}_{1}$ $\left(\mathrm{m}_{2}, \sigma_{2}\right.$, and $\left.\mathrm{S}_{2}\right)$ are the mean, the standard deviation, and the frequency of absolute cold events in cold climate (warm climate). $\mathrm{S}_{1}<\mathrm{S}_{2}$ indicates a negatively skewed distribution and includes more absolute cold events, implying an adaptive effect of a longer cold tail, i.e., more frequent relatively cold events. more absolute cold events than the normal distribution (i.e., $\mathrm{S}_{1}<\mathrm{S}_{2}$ ). This suggests that there might be an "adaptive" effect on reduction in the frequency of the absolute cold events as the climate is warmer and the distribution is skewed. Without the expansion of the cold tail (i.e., the increase in the frequency of the relatively cold events) followed by the change of skewness, the decrease in the absolute cold events would have been more intense. Such adaptation may reduce the costs of climate change impacts (IPCC 2007).

\section{CONCLUSION}

There is an increasing trend in the occurrence of the relatively cold events in association with the increasing mean temperature and decreasing variance. This trend is found more dominantly north of $40^{\circ} \mathrm{N}$ in East Asia, where the stronger warming signal is observed. The increase in the frequency of relatively cold events accompanied by the decreases in variance and the frequency of relatively warm events clearly demonstrates that the temperature distribution in East Asia during warmer winter does not follow a normal distribution with a symmetric shape, but in reality, has an asymmetric shape (i.e., skewed distribution). The frequency of relatively cold events is found to respond mainly to the variance of the $\mathrm{SH}$ and the mean $\mathrm{AO}$. The increasing trend in the frequency of relatively cold events is what we call "adaptive" change, as it is contrary to the warmer climate and corresponding atmospheric circulation changes in East Asia during winter. Therefore, the adaptive change may serve to partly countervail the decrease (-1.12 days per decade) in the frequency of absolute cold events over the entire observation period.

Acknowledgements This work was funded by the Korea Meteorological Administration Research and Development Program under grant CATER 2006-4204. We thank Prof. Chun-Chieh $\mathrm{Wu}$, Dr. Mon-Ming $\mathrm{Lu}$, and two anonymous reviewers for their helpful comments.

\section{REFERENCES}

Davis, R. E., 1976: Predictability of sea surface temperature and sea level pressure anomalies over the North Pacific Ocean. J. Phys. Oceanogr., 6, 249-266, doi: 10.1175/ 1520-0485(1976)006<0249:POSSTA >2.0.CO;2. [Link]

Garreaud, R. D., 2001: Subtropical cold surges: Regional aspects and global distribution. Int. J. Climatol., 21, 11811197, doi: 10.1002/joc.687. [Link]

Gong, D. Y. and C. H. Ho., 2004: Intra-seasonal variability of wintertime temperature over East Asia. Int. J. Climatol., 24, 131-144, doi: 10.1002/joc.1006. [Link]

Gong, D. Y., S. W. Wang, and J. H. Zhu, 2001: East Asian winter monsoon and Arctic Oscillation. Geophy. Res. Lett., 28, 2073-2076, doi: 10.1029/2000GL012311. [Link]

Higgins, R. W., A. Leetmaa, and V. E. Kousky, 2002: Relation- 
ship between climate variability and winter temperature extremes in the United States. J. Climate, 15, 1555-1572, doi: 10.1175/1520-0442(2002)015<1555:RBCVAW >2.0. $\mathrm{CO} ; 2$. [Link]

IPCC, 2007: Climate change 2007: The physical science basis. Cambridge University Press, Cambridge, United Kingdom and New York, NY, USA, 996 pp.

Jeong, J. H. and C. H. Ho, 2005: Changes in occurrence of cold surges over East Asia in association with Arctic Oscillation. Geophy. Res. Lett., 32, L14704, doi: 10.1029/2005 GL023024. [Link]

Jeong, J. H., B. M. Kim, C. H. Ho, D. Chen, and G. H. Lim, 2006: Stratospheric origin of cold surge occurrence in East Asia. Geophy. Res. Lett., 33, L14710, doi: 10.1029/2006 GL026607. [Link]

Kalnay, E., M. Kanamitsu, R. Kistler, W. Collins, D. Deaven, L. Gandin, M. Iredell, S. Saha, G. White, J. Woollen, Y. Zhu, A. Leetmaa, R. Reynolds, M. Chelliah, W. Ebisuzaki, W. Higgins, J. Janowiak, K. C. Mo, C. Ropelewski, J. Wang, R. Jenne, and D. Joseph, 1996: The NCEP/NCAR 40-Year Reanalysis Project. Bull. Amer. Meteor. Soc ., 77, 437-431, doi: 10.1175/1520-0477(1996)077<0437:TNYRP >2.0. $\mathrm{CO} ; 2$. [Link]

Nakamura, H. and J. M. Wallace, 1991: Skewness of low-frequency fluctuations in the tropospheric circulation during the Northern Hemisphere winter. J. Atmos. Sci., 48, 1441 -
1448, doi: 10.1175/1520-0469(1991)048<1441:SOLFFI> 2.0.CO;2. [Link]

Park, T. W., J. H. Jeong, C. H. Ho, and S. J. Kim, 2008: Characteristics of atmospheric circulation associated with cold surge occurrences in East Asia: A case study during 2005/ 06 winter. Adv. Atmos. Sci., 25, 791-804, doi: 10.1007/ s00376-008-0791-0. [Link]

Robeson, S. M., 2002: Relationship between mean and standard deviation of air temperature: Implications for global warming. Clim. Res., 22, 205-213, doi: 10.3354/cr022205. [Link]

Thompson, D. W. J. and J. M. Wallace, 2001: Regional climate impacts of the Northern Hemisphere annular mode. Science, 293, 85-89, doi: 10.1126/science.1058958. [Link]

Wettstein, J. J. and L. O. Mearns, 2002: The influence of the North Atlantic-Arctic Oscillation on mean, variance, and extremes of temperature in the northeastern United States and Canada. J. Climate, 15, 3586-3600, doi: 10.1175/ 1520-0442(2002)015<3586:TIOTNA >2.0.CO;2. [Link]

Wu, B. Y. and J. Wang, 2002: Winter Arctic Oscillation, Siberian High and East Asian winter monsoon. Geophy. Res. Lett., 29, 1897, doi: 10.1029/2002GL015373. [Link]

Zhai, P. M., A. J. Sun, F. M. Ren, X. N. Liu, B. Gao, and Q. Zhang, 1999: Changes of climate extremes in China. Clim. Change, 42, 203-218, doi: 10.1023/A:1005428602279. [Link] 